\title{
O trabalho do psicopedagogo na educação infantil de crianças com deficiências
}

(The work of psychopedagogues in early childhood education for children with disabilities.)

\author{
Marcleyde Almeida Do Nascimento \\ Faculdade de Escada (FAESC), Cabo de Santo Agostinho ( Brasil) \\ marcleydeuaa@yahoo.com
}

Fecha recepción: 01-03-2019

Páginas 83-97

Fecha aceptación: 20-05-2019

\section{Resumo.}

Este artigo tem a finalidade de pesquisar o trabalho do psicopedagogo na educação infantil de crianças com deficiências na Educação Infantil, tendo como objetivos determinar a contribuição do psicopedagogo na aprendizagem e na inclusão de alunos com deficiência da Educação Infantil. Os sujeitos envolvidos em nesse artigo são psicopedagogos, professores e pais de crianças com deficiência do Cabo de Santo Agostinho. O estudo revelou que a atuação dos psicopedagogos nos espaços escolares principalmente nos anos iniciais da Educação Infantil, é muito importante para 0 desenvolvimento e 0 processo de inclusão. Percebemos através deste contexto que a inclusão é um processo importante para o desenvolvimento das crianças com deficiência e que o psicopedagogo e a escola têm um papel fundamental nesse processo de inclusão.

Palavras chave: psicopedagogia; inclusão; educação infantil; criança com deficiência

\begin{abstract}
.
The purpose of this article is to investigate the work of the psychopedagogue in the early childhood education of children with disabilities in Early Childhood Education, whose objectives are to determine the contribution of the psychopedagogue in the learning and inclusion of students with disabilities in Early Childhood Education. The subjects involved in this article are psychopedagogues, teachers and parents of children with disabilities in Cabo de Santo Agostinho. The study revealed that the performance of psychopedagogues in school spaces, especially in the early years of Early Childhood Education, is very important for the development and inclusion process. We realize through this context that inclusion is an important process for the development of children with disabilities and that the psycho-pedagogy and school play a fundamental role in this inclusion process.
\end{abstract}

Keywords: educational psychopedagogy; inclusion; child education; children with disabilities. 


\section{Introdução.}

A educação inclusiva é uma necessidade da sociedade atual, ela é uma ação política, cultural, social e pedagógica. A Constituição Brasileira (1988) estabelece em seu artigo 206, inciso I a "igualdade de condições de acesso e permanência na escola" como um dos princípios para o ensino, e como dever do Estado, a oferta do atendimento educacional especializado, preferencialmente na rede regular de ensino (art.208), possibilitando aos pais ou responsáveis de crianças com deficiências 0 acesso no espaço escolar. Segundo Batista (2008, p.121).

"A inclusão escolar não significa desconsiderar as especificidades e necessidades educacionais de cada aluno. Pelo contrário, inclusão significa preservar os direitos dos alunos de frequentar as escolas comuns e atender às necessidades específicas para que cada aluno alcance seu pleno desenvolvimento".

Encontramos também respaldo na LDB (Leis de Diretrizes e Bases) lei $n^{\circ}$ 9.394/96 que garante 0 acesso à escola a toda criança de 0 a 5 anos e 11 meses anos de idade. É na educação infantil, etapa inicial da educação básica, que o aluno desenvolve a formação moral, o sentido da responsabilidade, fomentando a interação em grupos sociais diversos, tendo em vista o desenvolvimento da sociabilidade. Nesse contexto, encontramos 0 ambiente adequado para a inclusão das crianças com deficiência desta faixa etária. O Estatuto da Criança e do Adolescente- (ECA) lei $\mathrm{n}^{\circ} 8.069 / 90$ no art. 55, reforça os dispositivos legais ao determinar que "os pais ou responsáveis tem a obrigatoriedade de matricular seus filhos ou pupilos na rede regular de ensino". No entanto, em nossa prática, dificilmente encontramos nas salas de aula da educação infantil crianças com deficiência.

Segundo o Censo Demográfico (2015, p.2) apresenta $(17,4 \%)$ de criança com deficiência em Pernambuco. A presença de crianças de $O$ a 5 anos e 11 meses na educação infantil é fundamental, pois é nessa idade que a criança inicia seus primeiros passos na vida escolar, sendo crucial para o desenvolvimento de muitas habilidades, entre elas a tolerância, o respeito ao outro e a aceitação sem preconceitos, tornando este ambiente 0 espaço adequado para a interação entre as criança com deficiência e as crianças ditas "normais". A Lei 9.394/96 garante as crianças com deficiências 0 direito a ingressar nas salas de educação infantil com a intenção de integrar as demais crianças, eliminando todo tipo de discriminação existente na nossa sociedade, no entanto, é importante que as famílias conheçam os direitos de suas crianças e façam uso dos instrumentos legais para garantir esses direitos. Quando as famílias das crianças $\mathrm{cm}$ deficiência negam-lhes a possibilidade de participarem ativamente do espaço escolar e não os matriculam na rede regular de ensino, não sabemos se por falta de conhecimento das leis, se por acharem que seus filhos não são capazes de aprender, ou se a escola não se encontra preparada para recebê-los, estão na verdade privando-os de participarem de forma efetiva na sociedade, e de se desenvolverem como indivíduos integrais. 
$\mathrm{Na}$ sociedade ainda é frequente as discriminações e a indiferença é muito presente no cotidiano dessas crianças, e isto se reflete na instituição escolar que muitas vezes não se sente preparada para acolhê-las adequadamente. 0 acesso rápido as informações e a facilidade de comunicação da atualidade se configuram em um dos caminhos de superação dessas dificuldades sendo uma forma de romper as barreiras do pensamento discriminatório da sociedade, contribuindo para formação de cidadãos realmente conscientes, sendo um fator positivo tanto para as pessoas ditas "normais" quanto para as crianças com deficiência. A família é fundamental para o desenvolvimento da criança especial, pois, o apoio familiar em seu convívio, é mais um fator que colabora para desencadear o processo cognitivo, social e afetivo desta criança.

A aceitação, tanto da família, quanto da criança é essencial para estimular e desenvolver as diversas habilidades possíveis, ou seja, a família é um dos meios que faz parte desse desenvolvimento, pois ela é uma incentiva para a criança se sentir valorizada e incluída. Como podemos perceber, a participação familiar é fundamental, pois sua participação poderá promover a saúde física e mental da criança, o que poderá resultar num processo de aprendizagem bem mais eficiente. Embora, seja importante o processo de aceitação, percebemos que ainda existem impasses que dificulta a convivência das crianças com deficiência com a família. Segundo Góes (2005, p.2) "A confirmação de que a criança é portadora de deficiência mental se apresenta como um transtorno psicológico importante para a família", o que acontece geralmente, é que algumas famílias alimentam a crença que seu filho (a) com deficiência não têm capacidade de aprender.

"O avanço na legislação deveria representar um avanço na inclusão de pessoas com deficiências nos sistemas educacionais assim comose considerados os textos legais- $O$ acesso, a permanência e 0 sucesso escolar de alunos e alunas com deficiência deveriam estar representados no panorama educacional atual. Todavia, apesar de todo o arsenal legislativo, a realidade e os dados disponíveis revelam que, para a grande maioria da população, as leis e os procedimentos legais não são conhecidos e, consequentemente, os direitos das pessoas com deficiência continuam sendo violados de inúmeras formas" (Banco Mundial, 2013).

Por outro lado, temos avanços enquanto profissionais que podem atuar de forma mais complexa, no qual resulta 0 trabalho mais específico com alunos com deficiência, precisamente na modalidade infantil. $O$ referido profissional é 0 psicopedagogo que vem trazendo um novo olhar direcionado ao desenvolvimento educacional, cognitivo, afetivo e consequentemente aborda a inclusão. Assim também como atuação de uma vez detectada algo incomum utilizar 0 encaminhamento para necessárias intervenções. Para o autor Assis (2007):

[...] "apesar de a psicopedagogia ter surgido como uma disciplina complementar da psicologia e da medicina, devido à necessidade do 
atendimento ao aluno com dificuldade de aprendizagem, atualmente esse ramo preocupa-se não só com aluno e sua família, mas com tudo que o cerca, influencia e constrói a escola como instituição a comunidade onde estão inseridos, os professores, a equipe técnica administrativa. [...] dessa forma, é preciso lançar seu olhar para a comunidade, sociedade e a cultura. O foco deixa de ser apenas clínico torna-se também institucional" (pp.19-20).

A Psicopedagogia é concebida como a área que estuda 0 ato de aprender, entendendo-se 0 ato de aprender como os sentimentos, as ações, as elaborações do sujeito durante o seu processo de aprendizagem e a consciência que ele tem do que realiza. A intervenção psicopedagógico pode ser educacional ou clínica. É educacional quando estuda, analisa e propicia condições para que 0 aprendiz organize e elabore dados e informações, utilizando-os em sua vida.

Em busca de resposta para este artigo preparamos algumas hipóteses que teoricamente poderiam responder as nossas dúvidas sobre o problema que foram: a) de que forma a presença do psicopedagogo contribuem com processo de inclusão; b) qual a relação entre o psicopedagogo e a aprendizagem; c) quais os instrumentos utilizados pelo psicopedagogo na intervenção e encaminhamento.

Para analisar os argumentos expostos como justificativa é importante deixar claro que 0 objeto deste estudo em destaque nesse caso é o trabalho do psicopedagogo na Educação Infantil de crianças com deficiências. Inserida a relevância social por essa temática que decorre de nossa experiência profissional e da preocupação com o desenvolvimento completo das crianças de Educação Infantil utilizamos diversas fontes de informações buscando explorar por diversos fenômenos estudados para que possamos gerar a pergunta problema deste artigo que é: Como vem ocorrendo 0 trabalho do psicopedagogo com a inclusão de crianças com deficiências na Educação Infantil?

Por tanto, com a intenção de destacar aos questionamentos elencado $O$ objetivo geral que norteia o nosso trabalho é: determinar a contribuição do psicopedagogo na aprendizagem e na inclusão de alunos com deficiência da Educação Infantil. Em nosso estudo adotamos como objetivos específicos: investigar os procedimentos adotados pelo psicopedagogo na intervenção escolar; verificar o desenvolvimento dos alunos com deficiências através do psicopedagogo no espaço escolar.

Diante desta temática, nossa pesquisa justifica-se pelo fato de tentar compreender 0 trabalho do psicopedagogo com a inclusão de crianças com deficiência nas salas de educação infantil, como também para auxiliar pais e professores a refletir sobre a inclusão e o seu papel na formação dessas crianças. Iremos discutir na abordagem de discursão os seguintes: o trabalho do psicopedagogo, contribuições do psicopedagogo no contexto escolar no processo de inclusão na Educação Infantil, pessoa com deficiência e o processo de inclusão, a legislação e a educação inclusiva, Educação Infantil e Relação da Família e o psicopedagogo na escola. 


\section{1.-0 trabalho do psicopedagogo.}

O psicopedagogo tem um papel em busca de propor investigações capazes de desencadear um novo processo de aprendizagem no individuo. No entanto 0 psicopedagogo deve utilizar recursos como: testes, desenhos, história, atividades pedagógicas jogos, brinquedos etc. esses recursos constituem um importante instrumento, com base nesses dados é elaborado o plano de intervenção.

A Psicopedagogia clínica procura compreender de forma ampla e integrada os processos cognitivos, emocionais, sociais, culturais e pedagógicos que interferem no aprendizado com o objetivo de facilitar situações que favoreçam o desenvolvimento da criança em conjunto, com integração entre pais, professores e demais profissionais que transitam no espaço escolar.

Na escola o psicopedagogo também utiliza importantes instrumentos específicos de avaliação e estratégias que possibilite 0 atendimento dos alunos em sua individualidade, para desenvolver a sua produção escolar, diante disso atende 0 objetivo significativo ao ato de aprender. De acordo com Bossa, (2000). Cabe ainda, ao Psicopedagogo assessorar a escola, alertando-a para o papel que lhe compete, seja reestruturada a atuação da própria instituição junto ao aluno e professores, seja ainda redimensionado o processo de aquisição e incorporação do conhecimento dentro do espaço escolar, seja encaminhando aluno para outros profissionais. Durante sua atuação no espaço escolar, junto aos alunos com dificuldades de aprendizagem, o psicopedagogo consegue desenvolver tanto a aprendizagem de aluno com auxiliar o professor que muitas vezes sente-se frustrado por não conseguir que esses alunos acompanhem 0 desenvolvimento da turma. 0 trabalho do psicopedagogo é fundamental no ambiente escolar, pois garante a todos os alunos a oportunidade de aprenderem independentemente de suas limitações. Cada criança tem 0 processo de desenvolvimento diferente, algumas aprendem com mais facilidade enquanto outras aprendem mais devagar. E nesse momento que é de fundamental importância que o professor integrado com 0 psicopedagogo analise individualmente cada criança para poder adequar os conteúdos conforme a necessidade de cada um.

As mudanças de estratégias de ensino podem contribuir para que todos aprendam. Em alguns casos, as estratégias de ensino não estão de acordo com a realidade do aluno fazendo com que o processo de inclusão seja negativo, já que não atende a necessidade do contexto do sujeito envolvido. Vieira, (2004) corrobora:

O processo de ressignificação da prática pedagógica se constrói por meio de um processo que se efetiva pela reflexão critico-reflexiva do professor sobre seu próprio trabalho, isto é, a partir da base do contexto educativo real, nas necessidades reais dos sujeitos, nos problemas e dilemas relativos ao ensino e à aprendizagem (86). 
O professor não apenas transmite os conhecimentos ou faz perguntas, mas também ouve 0 aluno, deve dar-he atenção e cuidar para que ele aprenda a expressar-se, a expor suas opiniões. Acrescenta Firmino (2001 p. 121):

As evidências sugerem que um grande número de alunos possui características que requerem atenção educacional diferenciada. Neste sentido, um trabalho psicopedagógico pode contribuir muito, auxiliando educadores a aprofundarem seus conhecimentos sobre as teorias do ensino e aprendizagem e as recentes contribuições de diversas áreas do conhecimento, redefinindo-as e sintetizando-as numa ação educativa.

No entanto, torna-se 0 processo de desenvolvimento mais eficaz, quando 0 psicopedagogo atua e contribui junto com o educador em parceria e ambos objetivos são voltados para 0 principal motivo, 0 sujeito envolvido na ação educativa significativa.

\section{Contribuições do psicopedagogo no contexto escolar no processo de inclusão na educação infantil.}

O psicopedagogo pode atuar em diversas áreas no espaço escolar, de forma preventiva, para compreender os processos de desenvolvimento da aprendizagem nas series iniciais da educação infantil, no entanto, é preciso recorrer a várias estratégias para atender a necessidade dos alunos. O psicopedagogo precisa desempenhar atitudes que promova 0 processo de inclusão, assessorando os professores a lidar com 0 processo vinculando a aprendizagem significativa, respeitando a fase de desenvolvimento da criança. Vale ressaltar de que o fazer psicopedagógico seja capaz de transformar o conhecimento, tornando seus métodos em uma ferramenta eficaz na construção da aprendizagem. No entanto, cabe ao psicopedagogo perceber eventuais dificuldades no processo de inclusão. De acordo com Morin, (2000):

Cabe ressaltar a necessidade de um diagnóstico diferencial, que vise identificar os transtornos específicos, diagnósticos esse pertencente aos profissionais de diferentes áreas de saber, inserido como diagnósticos complementares à avaliação psicopedagógico (p 83).

As vantagens desses diagnósticos propõem ao psicopedagogo trabalhar o processo de inclusão nas series iniciais, preparando o sujeito a frequentar o espaço escolar sem alterar o vínculo de integração do professor, família e os demais que circulam nas instituições de ensino. Quando 0 psicopedagogo percebe que a criança apresenta algumas características diferenciadas, pode-se então, realizar alguns diagnósticos para intervir de forma positiva a inclusão da mesma no espaço escolar. Através de algumas avaliações com casos clínicos, pretende-se facilitar a compreensão da proposta psicopedagógico e de como o problema de aprendizagem pode ocorrer em função de algumas características variadas, embora possam aparecer normais dentro das funções, elas são significativamente de ordem 
diferentes, permitindo acreditar nas possibilidades que tem o ser humano em toda sua complexidade ao conhecimento e aprendizagem.

Diante disso, encontramos o papel no psicopedagogo que para nos auxiliar nos desafios diários de educar a psicopedagogia surge a partir da dinâmica de relações entre o sujeito e o meio familiar e social em que vive. A psicopedagogia pode trazer importantes contribuições para a Educação Infantil. Com a sua ação pedagógica e através de reflexões com o professor sobre o desenvolvimento do grupo de alunos e na elaboração de propostas adequadas para que avancem nas suas aprendizagens e também contribuir com conhecimentos da psicopedagogia. O psicopedagogo tem a possibilidade de direcionar o seu trabalho para a formação continuada do educador, com 0 objetivo de promover a sua aprendizagem, e, consequentemente, a aprendizagem de seus alunos. A partir dessa reflexão, concorda-se com as seguintes palavras:

[...] a busca de alternativas para a formação dos educadores de creches/pré-escolas e uma das tarefas mais importantes do psicopedagogo preocupado com o caráter preventivo de sua prática nessas instituições. Investigar, analisar e pôr em prática novas propostas para uma formação de educadores que os habilite a estabelecer relações mais maduras e conscientes com as crianças e com a equipe escolar, apresenta-se então, como um dos mais fortes desafios ao psicopedagogo comprometido com a educação infantil em instituições (CAVICCHIA, 1996, p. 210).

\section{Pessoa com deficiência e o processo de inclusão.}

A ideia que se tinha de pessoas que não se enquadram dentro dos parâmetros da normalidade, denominava-se pessoas "deficientes". Esse termo é atualmente considerado inadequado, devido à carga negativa, depreciativa da pessoa, que foi ao longo dos anos se tornando cada vez mais rejeitada pelos especialistas da área e em especial pelos próprios portadores. O emprego desse termo acabava por rotular os portadores. Tal fato parece ser típico de uma sociedade preconceituosa e despreparada para conviver com a diversidade. Segundo Ribas (1996, p.63):

[...] ignorância não é atributo apenas dos mais pobres ou dos que têm menos estudo. É algo que está presente em todas as camadas sociais, em muitas famílias, grupos de empresários, funcionários do governo (federal, estadual ou municipal) e, até mesmo, em muitos médicos que não se especializaram em reabilitar pessoas portadoras de deficiência ou que não têm prática no tratamento de algumas restrições do corpo (leves ou profundas).

Diante disso, se faz necessário afastar o termo "deficiente" e adequar-se a novos conceitos a que se referem os termos portadores de necessidades especiais. (Ferreira e Guimarães, 2006): 
A Organização Mundial da Saúde (OMS) propõe os seguintes conceitos a seguir: Deficiência é toda perda ou anormalidade de uma estrutura ou função psicológica, fisiológica ou anatômica; Incapacidade é toda restrição ou falta (devido a uma deficiência) da capacidade de realizar atividades, na forma ou na medida em que se considera normal para o ser humano; Impedimento é situação desvantajosa para determinado individuo, em consequência de uma deficiência ou de uma incapacidade que Ihe limite ou impeça o desempenho de um papel que é normal em seu caso (em função da idade, sexo, fatores sociais e culturais).

O termo portador de necessidades especiais surgiu por volta de 1990, primeiramente para substituir o termo "deficiência". A expressão necessidades especiais surgiu na intenção de neutralizar a concepção negativa da terminologia adotada por distinguir 0 indivíduo em suas singularidades por apresentarem limitações. Segundo Sawrey e Telford, (1998, p.34) "A tendência atual é empregar termos estigmatizante, mais gentis e menos carregados emocionalmente em substituição aos mais antigos, que adquiriram conotações de desamparo e desesperança".

Com a necessidade de lançar novas concepções do termo, foi considerada a representação de diferentes segmentos da sociedade, empregando um termo que valorizasse 0 indivíduo produtivo, que embora tenha suas limitações não impede de desenvolver suas habilidades. Para Araujo, $(2003$, p.3) "Traz ao ser humano uma maior valorização da "pessoa" sendo a qualificação "deficiente" um complemento de ideia nuclear".

No entanto, o termo pessoa com deficiência traduz uma terminologia que expressa um respeito maior por este grupo de pessoas, retirando até mesmo um sentimento preconceituoso causado pelas terminologias antes utilizadas.

\section{A legislação e a educação inclusiva.}

A garantia de acesso e permanência nas escolas comuns regulares significa um patamar imprescindível de cidadania para as crianças com deficiências. $\mathrm{Na}$ modalidade infantil os alunos com deficiência tais têm a garantia de frequentar 0 espaço escolar desde os primeiros anos. Para Kirk e Gallaguer (1996, p.23) "A última tendência a ser mencionada vai ao sentido de se estabelecer programas para criança com deficiência na fase pré-escolar". As instituições de ensino da educação infantil assegurado por lei vêm criando e fortalecendo a importância da inclusão destas crianças no ambiente escolar nos anos iniciais. Segundo a lei $n^{\circ}$ 9.394/96 da LDB "A oferta de educação especial, dever Constitucional do Estado, tem início na faixa etária de 0 a 5 anos e 11, durante a educação infantil". A sua inclusão no ambiente escolar, deve oferecer condições de acessibilidade e possibilitar o preparo para inserção nos espaços sociais. A inclusão deve favorecer a eliminação de posturas 
excludentes, a partir da convivência social e no ambiente escolar, a criança aprende desde cedo a não discriminar. De acordo com a Resolução CNE/CEB (2006):

O atendimento escolar desses alunos terá inicio na educação infantil nas creches e pré-escolas, assegurando-Ihes os serviços de educação especial sempre que se evidencie, mediante avaliação e interação com a família e a comunidade, a necessidade de atendimento educacional especializado.

A criança com deficiência tem assegurado o convívio com a sociedade, percebendo a importância de interação entre a família e a comunidade escolar, com a finalidade de estimular, desenvolver e atender suas necessidades, pois segundo a Constituição no art. 205:

A educação, direito de todos e dever do Estado e da família, será promovida e incentivada com a colaboração da sociedade, visando ao pleno desenvolvimento da pessoa, seu preparo para o exercício da cidadania e sua qualificação para o trabalho (Brasil, 1988).

Ao garantir o direito de todos à educação, automaticamente a sociedade, escolas, professores, profissionais que atuam na área como o psicopedagogo e o Sistema Educacional precisam oferecer meios que incentive o desenvolvimento de valores e princípios para a efetivação da educação inclusiva promovendo a participação dos portadores inclusive preparando-os para o mercado de trabalho. $\mathrm{Na}$ legislação vigente em nosso país a criança é sujeito de toda a proteção que a lei pode the assegurar e o Estatuto da criança e do Adolescente (1990, p.13), estabelece em seu art. $3^{\circ}$ que:

A criança e o adolescente gozam de todos os direitos fundamentais inerentes á pessoa humana, sem prejuízo da proteção integral de que trata esta lei, assegurando-se Ihes, por lei ou por outros, meios, todas as oportunidades e facilidades, a fim de lhes facultar 0 desenvolvimento físico, mental, moral, espiritual e social, em condições de liberdade e de dignidade.

Ao assegurar todos esses direitos o ECA garante que a criança e 0 adolescente estão protegidos em seus direitos fundamentais e afirma em seu Art. 53 (p. 23) que "a criança e 0 adolescente tem direito à educação, visando ao pleno desenvolvimento de sua pessoa, preparo para o exercício da cidadania e qualificação para o trabalho", e, sem fazer distinção porque estes direitos são garantidos há todos, independente de qualquer condição, podendo ser entendida como uma lei que privilegia a inclusão.

A ECA foi elaborada com objetivo de garantir à proteção integral a criança e ao adolescente e deixa bem claro em seu Art. 54, inciso III, (p.22), que "e dever do Estado assegurar à criança e ao adolescente: $O$ atendimento educacional especializado as pessoas com deficiência preferencialmente na rede regular de ensino", efetivando desta forma a garantia destes direitos, sendo, urna ferramenta fundamental para a construção de uma educação de fato inclusiva. Em se tratando 
de garantias de direitos torna-se imprescindível citar o DCNEI (Diretrizes Curriculares Nacionais para Educação Infantil), (1998), que garante em seu art. $3^{\circ}$ inciso IV:

As propostas pedagógicas das instituições de Educação Infantil ao reconhecer as crianças como seres íntegros, que aprendem a ser e conviver consigo próprio, com os demais e o próprio ambiente de maneira articulada e gradual, devem buscar a partir de atividades intencionais, em momentos de ações, ora estruturadas, ora espontâneas e livres, a interação entre as diversidades áreas de conhecimento e aspectos da vida cidadã, contribuindo assim com 0 provimento de conteúdos básicos para a constituição de conhecimento e valores (p. 16-17).

Diante disso, percebe-se que a legislação busca garantir todos os direitos, tanto das pessoas com deficiência quanto das crianças ditas "normais", não fazendo distinção entre ambas, criando assim um cenário favorável ao processo de educação inclusiva em nossa sociedade. As Diretrizes Nacionais para Educação Especial na Educação Básica (2001, p.70), que asseguram:

A busca da identidade própria de cada educando, o reconhecimento e a valorização das suas diferenças e potencialidades, bem como de suas necessidades educacionais especiais no processo de ensino e aprendizagem, como base para a constituição e ampliação de valores, atitudes, conhecimentos, habilidades e competências.

Portanto, cabe à escola valorizar a identidade do aluno, o inserido no contexto social, percebendo-o como um sujeito ativo, resgatando sua cidadania.

\section{Educação Infantil.}

Considera-se como educação infantil o período de vida escolar em que se atende, pedagogicamente, crianças entre 0 a 5 anos e 11 meses, com a finalidade de promover a integração entre os aspectos físicos, emocionais, afetivos, cognitivos e sociais da criança, considerando que esta é um ser completo e indivisível, pois segundo a Constituição (Brasil, 1988):

A educação infantil, primeira etapa da Educação Básica, tem como finalidade o desenvolvimento integral da criança até seis anos de idade. em seus aspectos físico psicológico, intelectual e social, complementando a ação da família e da comunidade.

De acordo com o RCNEI (Referencial Curricular Nacional para Educação Infantil, 1998), é fundamental que as crianças venham a ingressar na educação infantil, pois ele ressalta que: 
$\mathrm{Na}$ instituição de educação infantil, pode-se oferecer às crianças condições para as aprendizagens que ocorrem nas brincadeiras e aquelas advindas de situações pedagógicas intencionais ou aprendizagens orientadas pelos adultos. É importante ressaltar, porém, que essas aprendizagens, de natureza diversa, ocorrem de maneira integrada no processo de desenvolvimento infantil (p.23).

Nesse sentido, as instituições de Educação Infantil devem ser vistas como ambiente adequado para as crianças, porque como espaço coletivo propicia a interação entre as crianças de diferentes realidades, pois a criança precisa ser vista como sujeito social e é no meio social que ela se desenvolve e constrói a partir das interações que estabelecem com as outras pessoas e com o meio em que vivem. De acordo com 0 Referencial Curricular Nacional para a Educação Infantil (RCNEI, 1998, p. 35):

Uma ação educativa comprometida com a cidadania e com a formação de uma sociedade democrática e não excludente deve, necessariamente, promover o convívio com a diversidade, que é marca da vida social brasileira. Essa diversidade inclui não somente as culturas, os hábitos e os costumes, mas também as competências, os particulares de cada um.

Aprender a conviver e relacionar-se com pessoas que possuem habilidades e competências diferentes, que possuem expressões culturais e marcas sociais próprias, é condição necessária para o desenvolvimento de valores éticos, como a dignidade do ser humano, o respeito ao outro, a igualdade e a equidade e a solidariedade. A criança que convive com a diversidade nas instituições educativas, poderá aprender muito com ela. Segundo ALVES, (2006 p.53):

A pessoa com deficiência tem que se sentir valorizada, importante, inteligente, capaz igual aos demais estudantes. Cada um possui limites, até os "ditos normais" também possuem, o que o professor não pode é enfatizar a limitação das pessoas e sim lhes mostrar que são capazes de evoluir sempre, que cada conquista não é o ponto final, é apenas o estímulo para buscar cada vez mais.

No que se refere às crianças que apresentam deficiência, o convívio com as outras crianças se torna benéfico na medida em que representa uma inserção de fato no universo social e favorece 0 desenvolvimento e a aprendizagem, permitindo a formação de vínculos estimuladores, e a comodidade com a diferença e 0 trabalho com a própria dificuldade.

\section{Relação da Família e o psicopedagogo na escola}

A família desempenha um papel importante na formação dos indivíduos uma vez que permite e possibilita a constituição de sua essencialidade. É nela que o homem concebe suas raízes e torna-se um ser capaz de elaboração de competências 
próprias. A família é, por conseguinte, a primeira instituição social formadora da criança. Dela depende em grande parte a personalidade do adulto que a criança virá a ser. A escola tem a necessidade de estar em perfeita sintonia com a família, pois ela é uma instituição que complementa a família e juntas torna-se um lugar agradável para as crianças. Essa relação contribui de forma significativa, a interação da criança com deficiência no convívio do espaço escolar, familiar e social, que possibilita 0 acesso às informações necessárias para o processo de inclusão.

Segundo Paro (1999, p.126):

A escola deve utilizar todas as oportunidades de contato com os pais, para passar informações relevantes sobre seus objetivos, recursos, problema e também sobre as questões pedagógicas. Só assim, a família irá se sentir comprometida com a melhoria da qualidade escolar e com o desenvolvimento do seu filho como ser humano.

Como podemos observar, a escola e a família deve manter uma boa relação na tentativa de alcançar o maior objetivo à criança, e para fortalecer em conjunto a melhoria na qualidade de ensino, o desenvolvimento e a construção do sujeito inserido no seu meio. Nesse cenário, é importante levar em consideração que em um trabalho especializado com crianças apresentando dificuldade de aprendizagem, não é suficiente transmitir aos pais as atividades específicas a serem realizadas, já que outros aspectos ligados à família, à escola ou a dificuldades em outras áreas do desenvolvimento também estão presentes até mesmo as dificuldades que alunos com deficiência possam apresentam, devido a supostas limitações diagnosticadas. Então, é necessário ouvir os pais, analisar a situação e buscar caminhos que facilitem o desenvolvimento global da criança. Neste contexto, acredita-se que um programa de intervenção familiar seja de fundamental importância para 0 desenvolvimento e aprendizagem da criança. 0 relacionamento familiar, a disponibilidade e interesse dos pais na orientação educacional de seus filhos, são aspectos indispensáveis de ajuda à criança. Em um trabalho de orientação a pais, é possível despertar a sensibilidade dos mesmos para a importância destes aspectos, dando-lhes a oportunidade de falar sobre seus sentimentos, expectativas, e esclarecendo-Ihes quanto às necessidades da criança e estratégias que facilitam 0 seu desenvolvimento. Coincide, na escola, o psicopedagogo observa e diagnosticar o sistema escolar e, então, cria condições favoráveis para a resolução dos problemas que surgem, fazendo com que o ensinar e 0 aprender se tornem comprometidos. Segundo Nascimento, o psicopedagogo na instituição escolar:

[...] é o profissional indicado para assessorar e esclarecer a escola a respeito de diversos aspectos do processo de ensino-aprendizagem e tem uma atuação preventiva. Na escola, o psicopedagogo poderá contribuir no esclarecimento de dificuldades de aprendizagem que não têm como causa apenas deficiências do aluno, mas que são consequências de problemas escolares. Seu papel é analisar e assinalar os fatores que favorecem, intervêm ou prejudicam uma boa aprendizagem em uma instituição. Propõe e auxilia no 
desenvolvimento de projetos favoráveis às mudanças educacionais, visando evitar processos que conduzam às dificuldades da construção do conhecimento. (Nascimento, 2013, p. 01).

É importante ressaltar da importância, da relação saudável entre família, escola e 0 psicopedagogo para evitar que o prejuízo recaia sobre o ser em formação, neste sentido é imprescindível à mediação do psicopedagogo na criação de uma relação dialógica entre a família e a escola, onde se estabeleça uma aceitação, de princípio, de parte a parte, favorecendo que esses sistemas constituam fronteiras flexíveis, quais as trocas resultem em um movimento de transformação mútua, sem necessidade de definir causas nem procurar culpas. O psicopedagogo, por sua vez, pode ajudar as partes implicadas a despirem-se de culpa e analisarem de forma mais objetiva o que está ocorrendo. A relação entre a família e a escola deve ser caracterizada pelo esforço comum em prol do desenvolvimento do aluno, o espaço escolar não deve manter o sintoma familiar, mas sim se apropriar de meios que favoreçam a transformação, 0 crescimento e a aprendizagem, no entanto 0 psicopedagogo possui um papel que destaca no sentido de cuidar de todos os processos de aprendizagem no interior da escola, isso significa da parceria entre docentes, gestão, discente e família para articular no processo escolar, contudo acarreta desempenhar estratégia para incluir no processo ensino aprendizagem a inclusão de alunos com deficiência.

É nesse contexto que a busca de resultado significativo vai perpassar uma qualidade de ensino aprendizagem, valorizando profissional que visa intermediar um melhor andamento no espaço escolar, entrelaçando a conjuntura entre família e o psicopedagogo na instituição de ensino, onde promove a reflexão que cada um tem seu papel, mas que está interligado nesse processo tanto para alunos com deficiência quanto alunos ditos "normais". No entanto, a psicopedagogia trabalha com uma concepção de aprendizagem segundo a qual participa desse processo um equipamento biológico com disposições afetivas e intelectuais que interferem na forma da relação do sujeito com o meio, sendo que essas disposições influenciam e são influenciadas pelas condições socioculturais do sujeito e do seu meio.

\section{Considerações finais.}

A partir desse artigo podemos considerar a importância do trabalho dos psicopedagogos voltados á Educação Infantil para crianças com deficiência. No decorrer desse artigo percebemos que a inclusão é uma necessidade da escola e da sociedade, mas é especialmente importante para as pessoas com deficiência que se sentem valorizados, respeitados e preparados para o exercício de sua cidadania. E que o psicopedagogo precisa englobar seus conhecimentos, para atuar e atender de forma significativa 0 processo de inclusão. A escola precisa desenvolver competências para favorecer a inclusão dessas crianças, porque é função da escola desenvolver ações visando à interação desses alunos, garantindo a construção do conhecimento. 
Entender que a pessoa com deficiência é dotado de limitações seria uma visão preconceituosa, pois quando eles são devidamente estimulados podem desenvolver diversas habilidades. A escola precisa desenvolver competências para favorecer a inclusão dessas crianças, porque é função da escola desenvolver ações visando à interação desses alunos, garantindo a construção do conhecimento. Quando nos propusemos a estudar o trabalho do psicopedagogo na Educação Infantil de criança com deficiência tínhamos como objetivo analisar a concepção de pais e professores e o psicopedagogo, com o objetivo de determinar a contribuição do psicopedagogo na aprendizagem e na inclusão de alunos com deficiência da Educação Infantil. Neste artigo discuti um pouco a contribuição que o psicopedagogo têm na diminuição da distância entre ao que se aplica à aprendizagem seja ela em caráter individual ou coletivo, e ao comprometimento e diálogo que a família deve ter com a escola. A psicopedagogia analisa que é necessário por fim, considerar o sujeito como um corpo dotado de emoções, sensações (boas ou más), e também de um organismo com muita inteligência e muita cultura.

Através de uma relação enriquecida com os profissionais da escola e as famílias. 0 psicopedagogo aproximando os pais da escola deve ajudar a esses, conhecer a ação educativa da escola onde seus filhos estão inseridos. Devem estabelecer um acordo comum, proporcionando assim a busca do bem estar entre ambas às partes. Portanto, a sociedade e a escola precisam repensar suas convicções, com a perspectiva de estarem abertas as mudanças em favor da inclusão, a escola com uma missão fundamental de adotar profissionais que facilite a compreensão melhor deste processo que só trará benefícios para todos. Considerando os resultados obtidos em nesse artigo, percebemos que o psicopedagogo tem um papel de grande relevância dentro das instituições de ensino, e a relação entre este profissional e famílias é um fator que se torna indispensável para o desenvolvimento ensino aprendizagem de alunos com deficiência, destacando na modalidade infantil, uma vez que é nessa modalidade de Ensino os primeiros passos de aluno na sua vida escolar.

Finalmente, a importância deste estudo para o pesquisador está na contribuição recebida e no conhecimento científico a partir da experiência vivenciada durante a pesquisa. Compreendemos a possibilidade da utilização desse trabalho para futuros estudos, contribuindo para o desenvolvimento de outras pesquisas e se refletir sobre o a importância do psicopedagogo no processo de inclusão.

\section{Referencias.}

Araújo, U.F. (1998). O déficit cognitivo e a realidade brasileira. In:Aquino, J.G. (org.). Diferenças e preconceito na escola: alternativas teóricas e práticas. São Paulo: Summus Editorial.

Araújo, A.S., Vieira, S.S., Lucena, J.B. (2017). Fatores condicionantes ao abandono do tratamento da Tuberculose relacionados ao usuário e à equipe de saúde. São Paulo: Editora Gente. 
Assis, A.L.A. (2007). Influências da psicanálise na educação: uma prática psicopedagógica. Curitiba: Ibpex.

Barbosa, I. R., Pereira, L.M.S., Medeiros, P.F.M., Valentim, R.S., Brito, J.M., Costa, I.C.C. (2013). Análise da distribuição espacial da tuberculose na região Nordeste do Brasil, 2005-2010. Maranhão: Epidemiologia e Serviços de Saúde. v.22, n.4, p.687-695.

Cavalcante, M.S. (2019). A Inclusão física numa visão de acessibilidade para pessoas com deficiência física na rede municipal de ensino de Alto Alegre/RR-Brasil. RIAI, Vol.5, 1.

Góes, F.A.B. (2005). Um Encontro Inesperado: uma Abordagem Psicanalítica. Recife: Imprensa Universitária.

Nascimento, F.D. (2013). O papel do Psicopedagogo na instituição escolar. Trabalho apresentado como requisito parcial para aprovação na disciplina de Psicopedagogia, Curso de Psicologia, Faculdade Integrada Aparício Carvalho (FIMCA), 2013.

Silveira, M.P.T., Adorno, R.F.R., Fontana, T. (2007). Perfil dos pacientes com tuberculose e avaliação do programa nacional de controle da tuberculose em Bagé (RS). Porto Alegre: Jornal Brasileiro de Pneumologia. v.33, n.2, p.199205. 